This item was submitted to Loughborough's Research Repository by the author.

Items in Figshare are protected by copyright, with all rights reserved, unless otherwise indicated.

\title{
Perceptual-cognitive expertise in golf putting
}

PLEASE CITE THE PUBLISHED VERSION

https://www.routledge.com/Routledge-International-Handbook-of-Golf-Science/Toms-MacKenzie-RobertsonLochbaum-Kingston-Fradkin/p/book/9781138189126

\section{PUBLISHER}

(c) Routledge

\section{VERSION}

AM (Accepted Manuscript)

\section{PUBLISHER STATEMENT}

This work is made available according to the conditions of the Creative Commons Attribution-NonCommercialNoDerivatives 4.0 International (CC BY-NC-ND 4.0) licence. Full details of this licence are available at: https://creativecommons.org/licenses/by-nc-nd/4.0/

\section{LICENCE}

CC BY-NC-ND 4.0

\section{REPOSITORY RECORD}

Carey, Laura M., Robin C. Jackson, Malcolm M. Fairweather, Joe Causer, and A. Mark Williams. 2019. "Perceptual-cognitive Expertise in Golf Putting". figshare. https://hdl.handle.net/2134/26798. 
To appear in: M. Toms (Ed.) Routledge International Handbook of Golf Science, Routledge, October 2017.

\section{Perceptual-Cognitive Expertise in Golf Putting}

Laura M. Carey ${ }^{1,2}$, Robin C. Jackson², Malcolm M. Fairweather ${ }^{1}$, Joe Causer ${ }^{3}$, A. Mark Williams ${ }^{4}$

${ }^{1}$ sportscotland institute of sport, ${ }^{2}$ Loughborough University, ${ }^{3}$ Liverpool John Moores University, ${ }^{4}$ The University of Utah

\section{Introduction}

In golf putting, 'reading the green' is a difficult task. A study of university golfers completing three-metre putts found they were significantly worse on severely-breaking (11\% success) and moderately-breaking putts (41\% success) than on flat putts (51\% success) (Wilson \& Pearcy, 2009). This chapter focusses on the perceptual-cognitive phase of putting preparation, the period in which golfers make decisions about the optimal path from the ball position to the hole, taking into consideration the slope, break, and green contours (Campbell \& Moran, 2014). In this phase, golfers attempt to determine the correct aim line and required force before taking up their putting stance in preparation for the putting stroke (van Lier, et al., 2011).

The aim of the chapter is to synthesise existing work to highlight how superior performance in putting has been captured and to consider findings in relation to expertise. To place this in context, there are few studies on this aspect of golf putting and researchers have highlighted the need to recognise that “...successful putting entails more than proficient movement control, but requires... skillful perception” (van Lier, et al., 2011, p. 349). Golf putting is a 
complex perceptual-cognitive skill owing to unpredictable environmental factors such as the strength and direction of the wind, the influence of other weather conditions on ambient light and putting surface characteristics, and the variable topology and grain of the green. It is, therefore, likely that the ability to 'read' a putt and select the most appropriate strategy is a significant determinant of expertise in putting (Pelz, 1994; Karlsen \& Nilsson, 2008).

\section{Review of Current Research}

Observation of world class golf putters operating within the rules that govern their behaviour reveals an evaluation process that is time constrained, ordered, and predictable. Accordingly, the expert performance approach, originally proposed by Ericsson and Smith (1991; see also Williams \& Ericsson, 2005) can be applied to compare the demands of expert golf putting with scientific studies in this area. A systematic review framework was applied based on the operational definition of the perceptual-cognitive phase of golf putting. Consistent with this definition, eye movements and other behaviours that occur after the golfer has taken up their putting stance are not considered in this chapter. Ten studies focusing on the perceptualcognitive phase of golf putting were identified, of which four focused on visual aspects of reading the slope of the green and six focused more broadly on thought processes during this preparation phase (for a summary, see Table 16.1). This section will first focus on findings regarding perceptual judgment accuracy and errors in green reading and will then consider evidence for the processes underlying performance.

Accuracy of perceptual judgments. Of the studies that have focused on judging the slope or 'break' of a putt, two examined expertise effects (Pelz, 1994; Campbell \& Moran, 2014), one focused on alignment errors using the 'plumb-bob’ technique (MacKenzie \& Sprigings, 2005), and one examined the contribution of green reading to putt distance 
variability in skilled golfers (Karlsen \& Nilsson, 2008). These studies primarily focused on performance measures, with the exception of Campbell and Moran, who also analysed concurrent visual gaze behaviour. Karlsen and Nilsson used a mathematical formula to estimate the proportion of variability in putt distance judgments explained by errors in green reading, putting technique and green inconsistency. They tested 43 skilled golfers' ability to judge distance on 40 putts encompassing a variety of lengths and slopes and used data from 30 repeated putts to the same target to calculate variability attributable to technique. Using simple subtraction, they calculated that green reading variability was the largest contributor to putt distance error in the 40 -putt test, accounting for $60 \%$ of the variance, considerably more than variability in putting technique (34\%) and inconsistencies of the putting surface (6\%). These results clearly establish the importance of the perceptual-cognitive phase of putt preparation in skilled golfers but not the extent to which it differs across the expertise spectrum. 


\begin{tabular}{|c|c|c|c|c|}
\hline Authors & Participants & Measures & Task & Results \\
\hline Pelz (1994) & $\begin{array}{l}\text { Amateurs ( } n=179) \text {, } \\
\text { PGA club } \\
\text { professionals ( } n= \\
\text { 128) and PGA Tour } \\
\text { professionals ( } n= \\
6)\end{array}$ & $\begin{array}{l}\text { Estimation of } \\
\text { putt break }\end{array}$ & $\begin{array}{l}4 \text { to } 40 \text { holes; straight } \\
\text { to severely sloped } \\
\text { putts of } 3 \mathrm{~m} \text { to } 4.5 \mathrm{~m} \text {. }\end{array}$ & $\begin{array}{l}\text { Accuracy: Tour } \\
\text { professionals }>\text { Club } \\
\text { professionals }> \\
\text { Amateurs. }\end{array}$ \\
\hline $\begin{array}{l}\text { Mackenzie and } \\
\text { Sprigings } \\
(2005)\end{array}$ & $\begin{array}{l}\text { Golf experience not } \\
\text { specified }(n=31)\end{array}$ & $\begin{array}{l}\text { Plum-bob } \\
\text { separation; } \\
\text { perpendicular } \\
\text { stance } \\
\text { alignment } \\
\text { error }\end{array}$ & $\begin{array}{l}\text { Reading } 6 \times 1.4 \mathrm{~m} \\
\text { putts }\left(0^{\circ} \text { or } 10^{\circ} \text { slope }\right) \\
\text { from platform }\left(-10^{\circ} \text { to }\right. \\
\left.12^{\circ}\right) .\end{array}$ & $\begin{array}{l}\text { Significant error } \\
\text { when judging from } \\
\text { sloped platform; } \\
\text { error in judging } \\
\text { perpendicular stance. }\end{array}$ \\
\hline $\begin{array}{l}\text { Karlsen and } \\
\text { Nilsson (2008) }\end{array}$ & $\begin{array}{l}\text { High-skilled }(N= \\
43, \text { handicap }=2.8)\end{array}$ & $\begin{array}{l}\text { Putt distance } \\
\text { variability }\end{array}$ & $\begin{array}{l}40 \text { putts, } 2.2 \text { to } 19.3 \mathrm{~m} \\
\text { (uphill, downhill with } \\
\text { right and left breaks) } \\
\text { on two-tiered grass } \\
\text { practice green. }\end{array}$ & $\begin{array}{l}\text { Predictors: green } \\
\text { reading }(60 \%)> \\
\text { technique }(34 \%)> \\
\text { green inconsistency } \\
(6 \%) .\end{array}$ \\
\hline $\begin{array}{l}\text { Cotterill et al. } \\
\text { (2010) }\end{array}$ & $\begin{array}{l}\text { International } \\
\text { amateurs }(n=6 \text {, } \\
\text { handicap }=+1.5)\end{array}$ & $\begin{array}{l}\text { Retrospective } \\
\text { think-aloud } \\
\text { protocols }\end{array}$ & $\begin{array}{l}\text { Driving, chipping, and } \\
\text { putting video clips. }\end{array}$ & $\begin{array}{l}\text { Shot selection: Task } \\
\text { demands and task } \\
\text { variability influenced } \\
\text { planning. }\end{array}$ \\
\hline $\begin{array}{l}\text { Calmeiro and } \\
\text { Tenenbaum } \\
\text { (2011) }\end{array}$ & $\begin{array}{l}\text { Beginners }(n=3 \text {, } \\
\text { no handicap) and } \\
\text { experienced ( } n=3 \text {, } \\
0 \text { to } 18 \text { handicap) }\end{array}$ & $\begin{array}{l}\text { Concurrent } \\
\text { verbal reports }\end{array}$ & $\begin{array}{l}20 \text { x } 12 \mathrm{ft} \text { putts (uphill, } \\
\text { downhill with right } \\
\text { and left breaks); } 4 \\
\text { positions; grass } \\
\text { practice green. }\end{array}$ & $\begin{array}{l}\text { Experienced > } \\
\text { Beginners for } \\
\text { gathering } \\
\text { information, } \\
\text { planning, knowledge } \\
\text { of results, and } \\
\text { diagnostic } \\
\text { statements. }\end{array}$ \\
\hline $\begin{array}{l}\text { Campbell and } \\
\text { Moran (2014) }\end{array}$ & $\begin{array}{l}\text { Tour professionals } \\
(n=17), \text { elite } \\
\text { amateurs }(n=14, \\
\text { handicap }=+1.1) \\
\text { and club amateurs } \\
(n=14 \text {, handicap = } \\
10.3)\end{array}$ & $\begin{array}{l}\text { Visual search } \\
\text { behaviour; } \\
\text { slope judgment } \\
\text { accuracy }\end{array}$ & $\begin{array}{l}\text { Reading a single putt } \\
\text { from six positions in a } \\
\text { virtual environment. }\end{array}$ & $\begin{array}{l}\text { Tour professionals } \\
\text { and elite amateurs } \\
\text { made fewer fixations } \\
\text { of longer duration. }\end{array}$ \\
\hline $\begin{array}{l}\text { Whitehead et } \\
\text { al. (2015) } \\
\text { Study } 1\end{array}$ & $\begin{array}{l}\text { Skilled ( } n=30 \text {, } \\
\text { handicap }=5.3) \text {, } \\
\text { and novices }(n=30 \text {, } \\
\text { no handicap) }\end{array}$ & $\begin{array}{l}\text { Concurrent } \\
\text { verbal reports }\end{array}$ & $\begin{array}{l}30 \text { x 3m putts; indoor } \\
\text { artificial surface. }\end{array}$ & $\begin{array}{l}\text { Skilled > Novices for } \\
\text { information } \\
\text { gathering and } \\
\text { planning statements. }\end{array}$ \\
\hline
\end{tabular}




\begin{tabular}{|c|c|c|c|c|}
\hline Authors & Participants & Measures & Task & Results \\
\hline $\begin{array}{l}\text { Whitehead et } \\
\text { al. (2015) } \\
\text { Study } 2\end{array}$ & $\begin{array}{l}\text { Skilled }(N=6 \text {, } \\
\text { handicap = 5.5). }\end{array}$ & $\begin{array}{l}\text { Concurrent } \\
\text { and } \\
\text { retrospective } \\
\text { (10 min, } 24 \mathrm{hr} \text {, } \\
48 \mathrm{hr} \text { ) verbal } \\
\text { reports. }\end{array}$ & $\begin{array}{l}\text { Six holes on a golf } \\
\text { course. }\end{array}$ & $\begin{array}{l}\text { Low similarity } \\
\text { between themes } \\
\text { identified using think } \\
\text { aloud and interview } \\
\text { protocols. }\end{array}$ \\
\hline $\begin{array}{l}\text { Whitehead et } \\
\text { al. (2016) } \\
\text { Study } 1\end{array}$ & $\begin{array}{l}\text { High skilled }(n=6 \text {, } \\
\text { handicap }=4.2) \text {, } \\
\text { and low skilled }(n= \\
6 \text {, handicap }=20.2)\end{array}$ & $\begin{array}{l}\text { Concurrent } \\
\text { verbal reports }\end{array}$ & $\begin{array}{l}\text { Six holes on a golf } \\
\text { course. }\end{array}$ & $\begin{array}{l}\text { Planning thoughts: } \\
\text { High-skilled > Low- } \\
\text { skilled. }\end{array}$ \\
\hline $\begin{array}{l}\text { Whitehead et } \\
\text { al. (2016) } \\
\text { Study } 2\end{array}$ & $\begin{array}{l}\text { High skilled }(n=8 \text {, } \\
\text { handicap }=2.3) \text { and } \\
\text { moderately skilled } \\
(n=8 \text {, handicap }= \\
9.6)\end{array}$ & $\begin{array}{l}\text { Concurrent } \\
\text { verbal reports }\end{array}$ & $\begin{array}{l}\text { Six holes in practice } \\
\text { and competition. }\end{array}$ & $\begin{array}{l}\text { High-skilled > } \\
\text { Moderately-skilled } \\
\text { for thoughts per putt, } \\
\text { planning, and } \\
\text { evaluation } \\
\text { statements. }\end{array}$ \\
\hline
\end{tabular}

Table 1: Summary of the ten identified studies exploring perceptual-cognitive expertise in golf putting. Handicap data refer to mean values. 
Regarding expertise effects, Pelz (1994) asked more than 179 amateurs, 128 club professionals, and six professional tour players to estimate the influence of lateral slope by indicating where they perceived their aim line should be in relation to the hole. Golfers judged a variable number of straight to severely sloping putts ranging from 3 to 4.5 metres in length taken to several of 40 hole locations. Pelz reported that all participants systematically underestimated the break of putts, on average reporting just 25\% of the true break regardless of skill level. Although the error decreased, participants continued to underestimate the break in regard to how they aligned the putter and the initial direction of the ball after contact. For putts with a break of more than $15 \mathrm{~cm}$, participants were far more likely to miss 'below' the hole ( $>84 \%)$ than above the hole $(<9 \%)$. Furthermore, professional tour players were found to be $2 \%$ more accurate than club professionals and $5 \%$ more accurate than amateurs.

In a more controlled test of green reading using a single putting green displayed in virtual reality, professional golfers were found to be more accurate at reading the greens than elite amateurs and club golfers (Campbell \& Moran, 2014). In this study, participants were asked to 'tour' the green using six set positions then report precisely where they would aim to hole the putt. They were allowed six seconds at each position, following a circular route from crouching behind the ball to looking from the left side (standing), crouching behind the hole, standing behind the hole, looking from the right side, then lastly standing behind the ball. Campbell and Moran found that the professional golfers were accurate in reading $76.5 \%$ of putts, which was significantly higher than the accuracy attained by elite amateur and club golfers (57\%).

Golfers use a variety of ways to read the green. Popular methods include 'plumbbob’(MacKenzie \& Sprigings, 2005) and the certified instructor taught the method of 
‘AimPoint' (AimPoint, 2016). In the 'plumb-bob’ method, the golfer straddles an imaginary line between the hole, the ball, and him/herself, then hangs the putter at arm's length to align the bottom on the golf shaft with the centre of the ball (Foston, 1992). There is little formal evaluation of these methods; however, Mackenzie and Sprigings (2005) found that the plumb-bob method was inaccurate when the slope where the reading was taken from differed from the slope between the ball and hole. Also, they found that half the participants deviated by at least $1.5^{\circ}$ when attempting to take up a perpendicular stance to a platform angled $10^{\circ}$ from horizontal. The slopes in this study were extremely severe $\left(8^{\circ}\right.$ to $\left.12^{\circ}\right)$ and approximately five to seven times above the recommended limit of $1.7^{\circ}$ for real putting greens (Lemons, 2008), so the practical significance of these findings is questionable. Nonetheless, the error in stance for a $10^{\circ}$ slope was calculated to be equivalent to $8 \mathrm{~cm}$ of break for a $1.4 \mathrm{~m}$ putt. As standing perpendicular to the green is critical when using this method, even small errors may be potentially significant at the elite level.

Processes underlying perceptual-cognitive expertise. Six studies have employed verbal protocols to explore perceptual-cognitive processes underlying decision making (Cotterill et al., 2010; Calmeiro \& Tenenbaum, 2011; Whitehead et al., 2015; Whitehead et al., 2016). By analysing verbal protocols, researchers gain insight into performers' thought processes, and this requires participants to report their thoughts and explain their actions before, during or after the performance of the task. From this research, differences between higher- and lesser-skilled golfers have been identified. Calmeiro and Tenenbaum (2011) analysed concurrent verbal protocols from three novice and three experienced golfers as they completed 12-foot putts from four positions. The researchers grouped verbalisations into 'gathering information' (the search for relevant characteristics of the environment) and 'planning' (defining actions or strategies) and found that experienced golfers made 
significantly more of both types of statements than the beginner golfers. This finding was replicated in a larger scale study of skilled golfers who were found to make more frequent comments in regard to gathering information and planning shots (Whitehead et al., 2015; Whitehead et al., 2016). Furthermore, high-skilled golfers made more frequent use of planning statements than low-skilled golfers when putting on the course (Whitehead et al., 2016, Study 1).

An important consideration when conducting research using verbal protocols is whether different methodologies yield the same information. Cotterill et al. (2010) used interpretive phenomenological analysis to gather in-depth data from six elite amateur golfers on the psychological strategies used in their pre-performance routines for driving, putting and chipping. Regarding reading the green, the interviews revealed how the nature of the green can influence shot strategy and how one player attempted to visualise the path the ball would take rather than reading the line of the putt. Research on the decision making processes in golf putting has revealed important differences between concurrent and retrospective verbal reports. Whitehead at al., (2015, Study 2) recorded concurrent 'think aloud’ Level 3 verbalisations from six skilled golfers and conducted three interviews 10 minutes, 24 hours, and 48 hours after the participants completed a truncated round of six holes on a golf course. Overall, the concurrent verbal reports yielded more in-depth data in comparison to retrospective reports from the interviews. The themes identified using the concurrent and retrospective methods were very different, with similarity scores ranging from $38 \%$ to $41 \%$. Verbalisations for the themes 'Score' and 'Pre-performance activity' (including thoughts about putt sequence, planning the putt and identifying a target to aim for) were mentioned less in the retrospective interviews than in the think-aloud condition. These findings highlight possible limitations associated with retrospective reports such as reliability and recall 
accuracy (Cumming et al, 2005), and the potential for response bias (Shiffman et al., 1997). Concurrent verbal protocols therefore currently offer the best method for capturing golfers’ verbalisable thought processes in their natural environment and with it the opportunity to use highly representative putting task (Magill, 2000).

In extending their research to consider the impact of competitive pressure, Whitehead et al. (2016, Study 2) examined differences in concurrent verbal reports as participants played six holes on a golf course in practice and competition formats. In the competition round, prizes of $£ 100, £ 70$, and $£ 30$ were offered to those finishing in the top three and participants were told that individual scores would be reported back to all participants the following week. For putting during practice, the proportion of holes on which the high-skilled group made planning statements (76\%) and evaluation statements (88\%) was significantly higher than the moderately-skilled group ( $40 \%$ and 56\%, respectively). Under competitive pressure, the highskilled group also made planning statements on more holes (79\%) than the moderately-skilled golfers (46\%). These results suggest that higher skilled players gather additional verbalisable planning and evaluation information. However, further research is required to establish a causal link with performance.

To evaluate information sources golfers draw from as they read the green, Campbell and Moran (2014) used eye tracking technology in a virtual reality study. Consistent with results from other sports, these data revealed that more skilled players (professionals and elite amateurs) made fewer fixations of longer duration than less-skilled (club) players. However, there was no difference between groups regarding where they looked. The sample as a whole spent approximately half their time fixating on the immediate region of the target and 
approximately $35 \%$ of their time fixating on the two-foot area leading to the target, with less than $15 \%$ of their time spent looking at the ball. Considered alongside group differences in green reading accuracy and thought processes inferred from verbal reports, this finding implies that green reading expertise is more to do with how long information is processed than simply knowing the information sources on which to focus.

Limitations in Current Perceptual-Cognitive Research. To consider the applicability of these studies to world class competitive golfers, it is important to consider the representativeness of the putting tasks used alongside potential methodological limitations. Factors such as the playing surface and response requirements affect task representativeness while the number of participants, how their putting expertise is determined, and testing protocol are also important methodological concerns. Attention to these factors helps ensure researchers do not unintentionally limit the understanding of perceptual-cognitive expertise and associated skill-based differences (Dicks et al., 2009).

Task representativeness. Depending on the specific research question, the full demands of green reading are likely best captured when the putting surface (and variability) is the same as that experienced on golf courses. Of the studies focused on perceptual aspects of green reading, two were conducted on grass putting greens (Pelz, 1994; Karlsen \& Nilsson, 2008), one used a putting green displayed in virtual reality (Campbell \& Moran, 2014) and one used wooden platforms (MacKenzie \& Sprigings, 2005). Of the studies focused on thought processes, five were conducted on grass putting greens either on a golf course (Cotterill et al., 2010; Whitehead et al., 2015, Study 2; Whitehead et al., 2016), or in a practice area (Calmeiro \& Tenenbaum, 2011) and one study used an artificial putting surface (Whitehead et al. 2015, Study 1). Regarding the putting surface, response requirements were therefore highly representative for most studies. Adding further quantitative information 
about green speed and slope would help facilitate comparison with conditions experiences in elite level competition.

The design and response requirements across the ten identified studies have included assessment over a range of slopes and distances, assessment of putts of the same distance but different slopes, assessment of multiple putts of the same distance, and assessment of a single putt in a virtual environment. In the on-course studies, some task designs were more highly representative as participants competed against each other in a natural environment, adhering to the rule requirement for 40 seconds per putt and employing a full pre-putt routine. While this might not always be possible or desirable, it is important to note the requirement for information gathering is largely eliminated when repeated putts are taken from the same position. For example, Karlsen and Nilsson (2008) found that distance variation on a sixmetre putt reduced substantially from the first to the second attempt but very little in 29 subsequent attempts, with no significant change in the last 15 attempts. Conversely, the study conducted on an indoor artificial putting surface used more participants but was less representative and used multiple putts from the same distance.

Methodological limitations. Regarding the expertise of participants, the studies have recruited participants ranging from novices to highly-skilled golfers and have included tour professionals, club professionals, elite amateurs, low-handicap golfers, and individuals with no previous golf experience. This range of expertise may help build a cross-sectional picture of how perceptual-cognitive variables differ as golfers become more proficient; however, different criteria have been applied when ascribing group labels. For example, golfers classified as 'novices' range from those with no previous playing experience to those with a mean handicap of approximately 20. Similarly, the label 'skilled' has been applied to golfers ranging in handicap from 18 to 5.3 and 'highly-skilled' to groups with mean handicaps from 
4.2 to plus 1.5. An additional limitation of classifying players by golf handicap is that handicap reflects all aspects of golf play so may lack sensitivity as an indicator of putting expertise. The participants’ current playing and practice activity (e.g., hours per week), current competitive level, and accumulated years of competitive playing experience were not reported in all studies. Having more detailed knowledge about golfers' practice and playing experience would provide additional information that might help researchers better delineate participants. For example, golfers with a richer variety of competitive playing experience will have been exposed to a greater variety of green surfaces and contours that may enhance their perceptual-cognitive expertise (Kenyon, 2008).

In regard to group size, one should be cautious about making inferences to the relevant populations when group size is small, and this has been the case in many of the studies reviewed. Exceptions include the study by Pelz (1994), which examined slope reading in hundreds of amateur golfers and club professionals but also included a group of six tour professionals. Whitehead et al. (2015, Study 1) also used large groups $(n=30)$ in their comparison of concurrent verbal protocols in skilled and novice golfers. In contrast, group sizes of three were used in the Calmeiro and Tenenbaum (2011) study and groups of three to eight were used in other studies that analysed verbal protocols (Cotterill et al., 2010; Whitehead et al., 2015, Study 2; Whitehead et al., 2016). In addition, some studies lacked comparison or control groups that would have facilitated skill-based comparisons.

Research on how players gather information from a range of sources as they plan to putt will only be accurate insofar as the task includes relevant sources of information. If a key source of information is degraded or missing, this may affect an individual's ability to explore and process the perceptual-cognitive information they would use on the golf course. Considering 
task representativeness on a macro level, virtual reality technology gives researchers the opportunity to present, manipulate and control topographical features of the green in a precise and systematic manner. The virtual environment also lends itself to gathering verbal report and/or eye tracking data that help further understanding of the perceptual-cognitive processes underlying green reading judgments. Campbell and Moran’s (2014) study provides a taste of the potential of this area. On a micro level, the ‘fidelity’ of virtual environments (i.e., their ability to accurately represent the (visual) environment they depict) is critical. An examination of how behavioural markers of perceptual-cognitive expertise differ in real and virtual environments is needed to advance understanding in this area.

Concurrent verbal protocols require participants to report their thoughts in a continuous ‘think aloud' manner (Ericsson \& Simon, 1993). Importantly, the evidence thus far indicates that capturing concurrent verbal reports before putting does not impair subsequent performance. Specifically, Whitehead et al. (2015, Study 1) compared the performance of novices and skilled golfers who were assigned to one of three groups: Level 2 verbalisation (say what you are thinking at all times before and after the execution of the putt); Level 3 verbalisation (same as Level 2 with additional explanations provided for actions); or a control group. Participants completed 3-metre putts on an artificial surface, and Whitehead et al. found that performance was the same across the three conditions. While this is encouraging, the detrimental effect of 'reinvesting' conscious control during proceduralised actions is well established (Masters, 1992; Flegal \& Anderson, 2008;) so as this area of research develops it is important to ensure there is no 'contagion' from obtaining verbal protocols while players prepare to putt. For example, Kinrade et al., (2010) developed a scale designed to measure individual differences in the propensity for reinvesting when making decisions. In their study examining verbal protocols in golf putting, Whitehead et al. (2016, Study 2) found that scores 
on the decision reinvestment subscale were strongly correlated with the increase in comments on technical instruction when under competitive pressure in a group of high-skilled players.

\section{Implications for the Game}

The conclusions that can be drawn at this stage are necessarily tentative, as research in this area is in its infancy. Nonetheless, the studies reviewed in this chapter have revealed differences between high- and less-skilled golfers in the green reading process. Specifically, as they read the green during practice and competition higher-skilled golfers engage in significantly more planning than do lesser-skilled golfers. Professionals are also more accurate than amateurs in their ability to judge the break of a putt (Pelz, 1994; Campbell \& Moran, 2014), while the difficulty of the putt sometimes affects skilled players’ putt strategy, such as whether or not to lag the putt (Cotterill et al., 2010). Expertise differences are reflected in some aspects of visual attention - more skilled players make fewer fixations of longer duration - but not in regard to the distribution of time they spend focusing on different areas. Collectively, these findings highlight the need to extend understanding of the nature of differences in perceptual-cognitive processes and how they are acquired.

In this chapter, we have argued that capturing the perceptual-cognitive demands of 'realworld' putting is crucial for developing a full understanding of the processes underlying expert putting preparation. Using a range of qualitative and quantitative research methods and multiple dependent variables (e.g., combining verbal protocols with eye-tracking and behavioural measures, and potentially electroencephalogram [EEG]) will help develop a more comprehensive understanding of observed behavioural effects. It would also help establish clearer links between thought content (and associated inferences), different perceptual-cognitive strategies, subsequent judgment accuracy, alignment accuracy and, 
ultimately, putting performance. Understanding these links will allow researchers to make and test specific predictions about interventions that help establish causality, a crucial step towards making evidence-based recommendations to coaches and golfers.

In developing a more comprehensive understanding, there are three further considerations. First, the influence of age on the acquisition, retention, and deterioration of perceptualcognitive expertise has yet to be examined in golf. Longitudinal research recording changes in perceptual-cognitive expertise over time, and research comparing the perceptual-cognitive expertise of players in junior, adult, and senior age groups (including Senior Tour Players) will further enhance understanding in this area. Second, researchers have calculated that caddies help to improve scoring by approximately one stroke per round after controlling for player quality, weather, tournament round, and course changes (Coate \& Toomey, 2012). The way in which golfers use their caddie either as a source of perceptual-cognitive expertise or as a source of feedback for their judgments, together with how perceptual-cognitive expertise develops in caddies themselves, remains under-explored. Third, it is likely that tour players develop highly refined perceptual-cognitive knowledge about greens while competing and can use this knowledge to improve their performance and to better adapt to the conditions. At this stage, knowledge on how the golfer acquires perceptual-cognitive expertise within a round or across a competition or from competition to competition, whereby the green characteristics can significantly vary is currently unknown. It would be of interest to examine the perceptual-cognitive strategies employed by tour players and the influence of these strategies on performance (current and future). For example, televised and live observations of golfers playing on the USPGA and Europeans Tours highlight that successful putters employ the perceptual-cognitive strategy of tracking the ball post-putt. Advantages in visually tracking the ball throughout its' journey to the hole may include useful online 
feedback relative to the putting action, and secondly, through the tracking response, a golfer can gain information about the green's surface and potentially recognise environmental variation including, topography and pace variations. To track the ball, the golfer's head and eye movements need to be scaled and timed to the external motion of the ball. Research into dynamic visual acuity (or an individual's ability to track a moving object) has found that dynamic acuity increases with practice (Long \& Riggs, 1991). To develop evidence-based recommendations that can help inform golfers and coaches, a greater understanding on how much practice a golfer needs to develop an effective tracking response and perceptualcognitive expertise is required. It is also unknown whether tracking your opponent's/playing partner's putt can help you to gain knowledge to inform your future putt on the same surface. Examining both performance and associated perceptual-cognitive processes and strategies associated with the transfer to novel conditions would further enhance knowledge in this area and help to define the perceptual-cognitive phases in golf putting, such as preparation and post-putt phases.

\section{Summary and Future Directions}

When designing perceptual-cognitive studies, it is important that the task is representative so that findings can be applied to the real world. A representative task might involve high variability in terms of putt difficulty (e.g., slope and distance), performed on a grass putting surface, using a regulation size hole, with each participant using their putter and preferred golf ball. Participants might also be required to adhere to PGA Tour regulations, and be free to move around the green, as they would do in a 'real world' circumstance. Alternatively, and depending on the research question, it may be appropriate to design a task that allows researchers to manipulate certain variables systematically in a controlled environment. Finally, qualitative research such as detailed interviews with targeted individuals, e.g., the 
best 'green readers' in the world or current tour players, would be highly informative, especially considering it is not currently possible to recreate the reality of tour level putting in a research laboratory setting. The circumstance of a tour player preparing to putt on the $18^{\text {th }}$ green, knowing that the consequences of holing the putt means a life changing difference (both financially and in future opportunities) is very different to associated competitive pressure generated in the current research. At this time, research on the perceptual-cognitive aspects of golf putting is limited. As more systematic and ecologically valid research is reported, with more representative task designs and different (or combined) methodologies, a more comprehensive evidence base will be established. This enhanced knowledge will enable researchers to make stronger evidence-based recommendations to golfers, coaches, and practitioners.

\section{References}

AimPoint. (2016) AimPoint. Get the Facts. Available from: http://www.aimpointgolf.com/ [Accessed February, 20 2016].

Calmeiro, L. \& Tenenbaum, G. (2011) Concurrent Verbal Protocol Analysis in Sport: Illustration of Thought Processes During a Golf-Putting Task. Journal of Clinical Sport Psychology, 5(3), 23-236.

Campbell, M.J. \& Moran, A.P. (2014) There Is More To Green Reading Than Meets The Eye! Exploring the Gaze Behaviours of Expert Golfers on a Virtual Golf Putting Task. Cognitive Processing, 15(3), 363-372.

Coate, D. \& Toomey, M. (2014) Do Professional Golf Tour Caddies Improve Player Scoring? Journal of Sports Economics, 15(3), 303-312.

Cotterill, S.T., Sanders, R. \& Collins, D. (2010) Developing Effective Pre-Performance Routines in Golf: Why Don’t We Ask the Golfer? Journal of Applied Sport Psychology, 
22(1), 51-64.

Cumming, J., Hall, C. \& Starkes, J.L. (2005) Deliberate Imagery Practice: The Reliability of Using a Retrospective Recall Methodology. Research Quarterly for Exercise and Sport, 76(3), 306-314.

Dicks, M., Davids, K. \& Button, C. (2009) Representative Task Designs for the Study of Perception and Action in Sport. International Journal of Sport Psychology, 40(4), 506524.

Ericsson, K.A. Simon, H.A. (1993) Protocol Analysis: Verbal Reports as Data, Cambridge: MA: MIT Press.

Flegal, K. \& Anderson, M. (2008) Overthinking Skilled Motor Performance: Or Why Those Who Teach Can’t Do. Psychonomic Bulletin \& Review, 15(5), 927-932.

Foston, P. (1992) The Encyclopedia of Golf Techniques: The Complete Step-By-Step Guide to Mastering the Game of Golf., Philadelphia: Courage Books.

Karlsen, J. \& Nilsson, J. (2008) Distance Variability in Golf Putting Among Highly Skilled Players : The Role of Green Reading. Annual Review of Golf Coaching, 71-80.

Kenyon, P. (2008) Distance Variability in Golf Putting Among Highly Skilled Players : The Role of Green Reading. Annual Review of Golf Coaching, 81-84.

Kinrade, N.P., Jackson, R.C., Ashford, K.J. \& Bishop, D.T. (2010) Development and Validation of the Decision-Specific Reinvestment Scale. Journal of Sports Sciences, 28 (10), 1127-1135.

Lemons, J. (2008) Putting Green Speeds, Slopes, and “Non-Conforming” Hole Locations. USGA Green Section Record, (July-August), 21-25.

Long, G.M., Riggs, C.A. (1991) Training effects on dynamic visual acuity with free-head viewing. Perception, 20, 363-371.

van Lier, W.H., van der Kamp, J. \& Savelsbergh G, J.P. (2011) Perception and Action in 
Golf Putting: Skill Differences Reflect Calibration. Journal of Sport \& Exercise Psychology, 33(3), 349-369.

MacKenzie, S.J. \& Sprigings, E.J. (2005) Evaluation of the Plumb-Bob Method for Reading Greens in Putting. Journal of Sports Sciences, 23(1), 81-87.

Magill, R.A. (2000) Augmented Feedback in Motor Skill Acquisition. In R. N. Singer, H. A. Hausenblas, \& Janelle C., eds. The Handbook of Research on Sport Psychology. New York: John Wiley \& Sons, Inc., 86-114.

Masters, R.S.W. (1992) Knowledge, Knerves and Know-How - the Role of Explicit Versus Implicit Knowledge in the Breakdown of a Complex Motor Skill Under Pressure. British Journal of Psychology, 83, 343-358.

Pelz, D. (1994) A Study of Golfers’ Abilities to Read Greens. In, Cochran, A.J. and Farrally, F.R. (eds.), Science and Golf II: Proceedings of the 1994 World Scientific Congress of Golf, London, E \& FN Spon, 180-185.

Shiffman, S. et al. (1997) Remember that? A Comparison of Real-Time Versus Retrospective Recall of Smoking Lapses. Journal of Consulting and Clinical Psychology, 65(2), 292300.

Whitehead, A.E., Taylor, J.A. \& Polman, R.C.J. (2015) Examination of the Suitability of Collecting in Event Cognitive Processes using Think Aloud Protocol in Golf. Frontiers in Psychology, 6, 1083 (12pp).

Whitehead, A.E., Taylor, J.A. \& Polman, R.C.J. (2016) Evidence For Skill Level Differences in the Thought Processes of Golfers during High and Low Pressure Situations. Frontiers in Psychology, 6, 1974 (12pp).

Williams, A.M. \& Ericsson, K.A. (2005) Perceptual-Cognitive Expertise in Sport: Some Considerations When Applying the Expert Performance Approach. Human Movement Science, 24(3), pp.283-307. 
Wilson, M.R. \& Pearcy, R.C. (2009) Visuomotor Control of Straight and Breaking Golf Putts. Perceptual \& Motor Skills, 109(2), 555-562. 